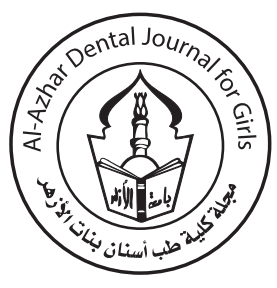

\title{
Time of Implant Placement in the Esthetic Zone: Does it affect the Thickness of the Labial Bone?
}

\author{
Hanaa M. Rabiae ${ }^{1 *}$, Fatma I. Mohamed ${ }^{2}$, and Nahed A. Abd Elmoniem³ ${ }^{3}$
}

Codex : 51/20.07

azhardentj@azhar.edu.eg

http://adjg.journals.ekb.eg

DOI: $10.21608 /$ adjg.2020.23230.1233

Oral Medicine \& Surgical Sciences (Oral Medicine, Oral \& Maxillofacial Surgery, Oral Pathology, Oral Biology)

\section{KEYWORDS}

Labial bone thickness (LBT),

Esthetic zone, Bovine bone graft substitute (BBGS).

\begin{abstract}
Purpose: to evaluate the labial bone thickness (LBT) in the esthetic zone of the maxilla after insertion of dental implants: immediately, 4-6 weeks, and 3 months after tooth extraction, by using cone beam computed tomography (CBCT). Patients and methods: Fifteen cases, who had single non-restorable upper anterior tooth or an extracted tooth not exceeding 3 months, were involved in the study. The patients were divided equally into three groups. In group 1 , implants were placed immediately after tooth extraction. In group 2, implants were inserted 4-6 weeks after extraction. In group 3 , implants were inserted 3 months following tooth extraction. All implants were covered by bovine bone graft substitute (BBGS) and platelet rich fibrin (PRF) membrane. The LBT was measured immediately after implant insertion, six and 12 months of surgery by using (CBCT). The patients were examined clinically by assessing probing depth (PD), sulcus bleeding index (SBI), pink esthetic score (PES), and visual analogue score (VAS). Results: Successful osseointegration was observed in all patients, both clinically and radiographically. There was insignificant difference in the labial bone thickness between the 3 groups; however, the amount of bone resorption was considered significant only in group 1 , at the implant shoulder, during the first interval of the follow up (immediate to six months postoperative). Conclusion: Preservation of LBT at the labial surface of the dental implants in the esthetic zone of the maxilla appears to be independent on the time of implant insertion after tooth extraction. It was possible to create and preserve a stable layer of labial bone over implant surface, by the application of BBGS and PRF membrane.
\end{abstract}

- Paper extracted from Master Thesis titled; (Time of Implant Placement in the Esthetic Zone: Does it affect the Thickness of the Labial Bone?)

1. MSc student, Department of Oral and Maxillofacial Surgery, Faculty of Dental Medicine for Girls, Al-Azhar University, Cairo, Egypt.

2. Assistant Professor of Oral and Maxillofacial Surgery Department, Faculty of Dental Medicine for Girls, Al-Azhar University, Cairo, Egypt.

3. Lecturer of Oral and Maxillofacial Surgery Department, Faculty of Dental Medicine for Girls, Al-Azhar University, Cairo, Egypt.

* Corresponding author email: mustafahanaa566@gmail.com 


\section{INTRODUCTION}

The most common causes of missing upper anterior teeth are trauma, failure of root canal treatment, root resorption, dental caries, and congenital missing of lateral incisor. Anterior esthetic zone of the maxilla requires very accurate preoperative assessment and planning before implant insertion, to achieve adequate esthetic and functional outcomes. The upper anterior teeth have a thin labial cortex, which has an uneven thickness along the entire length of the root, i.e. it is thin at the cemento-enamel junction $(<1 \mathrm{~mm})$ and becomes thicker more apically $(\geq 2 \mathrm{~mm})^{(1,2)}$. Tooth loss in the esthetic zone usually associated with significant bone resorption, especially at the labial side ${ }^{(3)}$. For this reason, preservation of adequate labial mucosa and peri-implant bone are important to achieve optimal esthetic results in this region. Several types of bone grafts are widely used in conjunction with dental implants to prevent alveolar bone resorption.

Based on the origin of the bone grafts, they are classified into four groups; autograft, allograft, xenograft, and alloplastic materials. Xenografts are derived from other species as bovine, porcine, and equine bone minerals. Bovine bone graft is the most commonly used type after being thermally and chemically treated to isolate the organic components, so the remaining inorganic constituent provides a natural architectural matrix and adequate source of calcium ${ }^{(4)}$. The inorganic component can preserve the three dimensions of the augmented region during the remodeling phase ${ }^{(5)}$.

Guided bone regeneration is a dental technique by which a barrier membrane is used to act as a stabilizer for the bone graft and to protect the regenerated site from non-osteogenic cells such as fibroblasts and epithelial cells ${ }^{(6)}$. Platelet rich fibrin (PRF) can be employed as a resorbable membrane to protect the bone graft in the process of guided bone regeneration ${ }^{(7)}$. It protects bone defects from non-desirable cells, provides a space for proliferation of osteogenic and angiogenic cells, and per- mits blood clot mineralization ${ }^{(8)}$. Furthermore, the addition of PRF to bone graft particles reduces the volume of needed particulate bone graft substitute, improves the vascularity of the regenerated defect by promoting angiogenesis, which in turn reduces the time needed for healing ${ }^{(9)}$.

Cone beam computed tomography (CBCT) has many applications in dental implantology as it allows measurement of the available bone height, width, and density, as well as identification and localization of the surrounding anatomical structures ${ }^{(10)}$. Furthermore, CBCT has been used to accurately measure the LBT before and after implant insertion $^{(11)}$. The assessment of labial bone thickness (LBT) during the follow up period of dental implants is of significant importance to predict reliability of treatment in the esthetic zone. For obtaining and maintaining optimal results in the esthetic zone, preservation and establishment of labial mucosa and the supporting labial bone should be considered ${ }^{(12)}$. So the aim of this study was to evaluate the LBT in the upper anterior esthetic zone after placement of implants immediately, 4-6 weeks (immediate delayed), and 3 months (delayed) after tooth extraction with the application of bovine bone graft substitute (BBGS) and PRF membrane.

\section{PATIENTS AND METHODS}

\section{Study Design and Population}

To address the purpose of this research, a prospective comparative study was designed and performed. The study population included 15 patients who required replacement of a single tooth in the esthetic zone. The patients were selected from the outpatient clinic of the Department of Oral and Maxillofacial Surgery, Faculty of Dental Medicine for Girls, Al-Azhar University, between January 2018 to September 2018. The following inclusion criteria included: (1) Patients with a single badly destructed upper anterior tooth or extracted tooth not exceeding 3 months, (2) patients with adequate 
mesiodistal width that permits crown restoration, (3) free from soft or hard tissue pathology, (4) good oral hygiene, (5) nonsmokers, (6) free from any local or systemic diseases which may affect the osseointegration of dental implants, and (7) patients with high motivation and cooperation ${ }^{(13)}$. The exclusion criteria included (1) alcohol or drug abuse, (2) pregnant patients, (3) patients with para-functional habits such as bruxism and clenching ${ }^{(14)}$. According to the time of implant insertion, the patients were equally divided into 3 groups; group 1: implants were inserted in the same visit immediately after extraction, group 2: implants were inserted after 4-6 weeks of extraction, and group 3: implants were inserted after 3 months of extraction. In accordance with the Declaration of Helsinki, written informed consent was taken from all patients, and the local ethics review committee of the Faculty of Dental Medicine for Girls at Al Azhar University approved the study.

\section{Surgical protocol}

\section{Presurgical preparation}

Preoperative CBCT was performed to all patients to evaluate the implant site and alveolar bone dimensions. Dental impressions were taken to make study casts at which waxing up and vacuum stent was fabricated. Before implant placement, all patients were asked to take a single dose of prophylactic antibiotic, one hour before surgery (Amoxicllin $875 \mathrm{mg}+$ Clavulanic acid 125mg).

\section{PRF Preparation}

PRF membrane was prepared from collecting 10 $\mathrm{ml}$ of patient's blood. The blood sample was centrifuged in a table centrifuge at 3000 revolutions per minute (rpm) for 15 minutes. The centrifuged product included three layers: (1) Acellular platelet poor plasma (PPP) is the most superficial layer, (2) A clot of PRF in the middle, and (3) RBCs at the bottom. The PRF was then separated from PPP and RBCs layer to be ready for use ${ }^{(15)}$.

\section{Surgical procedures}

All patients were treated under local anesthesia using Articaine 4\%, $40.00 \mathrm{mg}$ hydrochloride and Epinephrine 1:100,000. In group 1, atraumatic tooth extraction was performed by periotomes to preserve the labial bone. In all patients, crestal and two releasing incisions were done by using blade no 15 , and then followed by flap reflection and retraction. Vacuum stent was used for proper implant positioning in relation to the adjacent teeth. The drilling protocol was performed according to the instructions of the manufacturer. The implant was then placed into the prepared site. The bovine bone graft substitutes (BBGS) which is in the form of cancellous bone, free from cortical portion and organic elements ( $\mathrm{Ti}$ Oss, Octabone), was used in this study ${ }^{(16)}$. A 0.25 $\mathrm{gm}$ of the bone graft was mixed with saline to cover the labial bone surface and to obliterate the labial gap in cases of immediate implant (group 1), and finally PRF membrane was placed to cover the bone graft $^{(17)}$ as illustrated in figure (1). Wound closure was performed by using 3-0 non resorbable horizontal matress sutures. Postoperative analgesics and antibiotics were prescribed to reduce the rate of infection and for pain control. The oral hygiene measures were explained to all patients. During the osseointegration phase (first 6 months), patients were instructed to use a partial denture without interference with the implant site. Following this period, all patients were recalled for the second stage loading procedures.

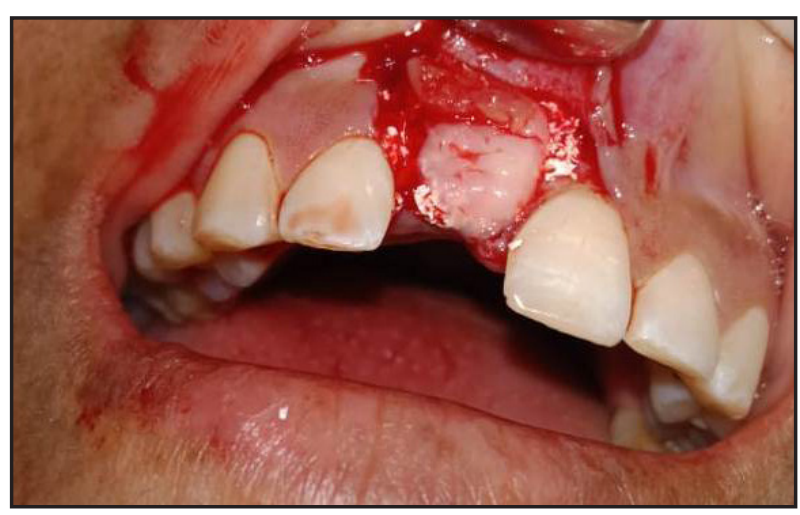

Figure (1): Image showing BBGS and PRF membrane over the implant 


\section{Clinical and radiographic evaluation}

All patients were evaluated clinically by assessing the probing depth (PD) and sulcus bleeding index (SBI) after six months of implant placement (i.e. after implant loading) and after 12 months of implant placement (i.e. after six months of implant loading). At the end of the follow up period, pink esthetic score (PES) (Belser et al., 2009) ${ }^{(18)}$ and patients' satisfaction by visual analogue scale (VAS) ${ }^{(19)}$ were also evaluated.

CBCT were performed for all patients at three time follow up periods: immediately after implant insertion, at six and 12 months postoperative. The focal planes of all CBCTs were adjusted to the center of the buccolingual aspect of the implant as well as the mesiodistal aspect. CBCTs were performed by using Planmeca Promax 3 D Mid, made in Finland. After acquisition, data was imported as DICOM file and then downloaded via a Compact Disk (CD) to a computer for analysis by using software (Planmeca Romxis viewer, launcher 4.6.0.R).

By using the measuring tools of the software, LBT was measured (in $\mathrm{mm}$ ); from the center of the labial surface of the implant to the labial bone surface at three points; at implant shoulder, 3 and, $5 \mathrm{~mm}$ apical to the shoulder. The amount of bone resorption was recorded by calculating the difference of the LBT records between immediate and six months (first interval), and between six and 12 months (second interval). All measurements were taken twice by the same investigator, two weeks apart, and the mean of the two records represented the final results.

\section{Statistical analysis}

All statistical analysis were performed by computer program IBM SPSS (statistical package for the social science; IBM corp, Armonk, NY, USA) for windows version 2 .

Data were statistically described as mean \pm standard deviation (SD), percentage, minimum and maximum. ANOVA test was used to compare the means of the study groups followed by Post Hoc test. Repeated measures ANOVA test followed by Mauchly's Sphericity test were used to compare the numerical variables along the study period. Paired student $(t)$ test was used with in the same group for comparison of numerical variables between two different time intervals. Chi-square $(\chi 2)$ test was used to compare the two or more qualitative data, or between qualitative and quantitative data. $P$-values below 0.05 were considered statistically significant.

\section{RESULTS}

Fifteen patients (10 females and 5 males) with badly decayed or extracted upper anterior teeth were included in this study. The mean of patients' age was $35.7 \pm 8$ years. The implant length was 13 $\mathrm{mm}$ for all implants and the diameter was $3.7 \mathrm{~mm}$ for central incisor and cuspid tooth $(80 \%)$ and 3.2 $\mathrm{mm}$ for lateral incisor (20\%). Central incisor was restored by dental implants in $53.3 \%$ of cases, $20 \%$ for lateral incisor, and $26.7 \%$ for cuspid tooth. The demographic and clinical data of the three groups are shown in tab (1).

\section{Postoperative clinical evaluation}

Surgical procedures were well tolerated by all patients without intra- and postoperative complications. The primary mechanical stability was achieved in all cases. The postoperative edema was minimal and subsided completely within one week. The postoperative pain and discomfort were mild and they were controlled by analgesics. At the time of suture removal, all mucosa had a normal appearance. Successful osseointegration was observed in all patients, both clinically and radiographically during the follow up period.

In all groups, PD values increased at the end of the follow up when compared to the six months records. These changes were considered significant in group $1(p$ value $=0.03)$ and non-significant in 
groups 2 and 3 ( $p$ value $>0.05$ ). When comparing the PD values in the three groups, the changes were considered statistically insignificant $(p$ value $=0.3$ ). At the 12 months postoperative, SBI values showed an improvement; however, the values were considered non-significant when compared in the three groups. In addition, both PES and VAS showed nonsignificant difference among the groups. Details of PD, SBI, PES, and VAS records are presented in Table 2.

Table (1) Demographic and clinical data of the study patients

\begin{tabular}{|c|c|c|c|c|}
\hline & Group 1 & Group 2 & Group 3 & $\begin{array}{c}P \\
\text { value }\end{array}$ \\
\hline Patients number & 5 & 5 & 5 & 1 \\
\hline Sex & & & & \multirow{3}{*}{0.8} \\
\hline Male & $2(40)$ & $2(40)$ & $1(20)$ & \\
\hline Female & $3(60)$ & $3(60)$ & $4(8)$ & \\
\hline Age & $31.8 \pm 8.6$ & $37.8 \pm 7.6$ & $37.6 \pm 8.0$ & 0.4 \\
\hline \multicolumn{4}{|l|}{ Implant site } & \multirow{4}{*}{0.9} \\
\hline Central incisor & $3(60)$ & $2(40)$ & $3(60)$ & \\
\hline Lateral incisor & $0(0)$ & $2(40)$ & $1(20)$ & \\
\hline Cuspid & $2(40)$ & $1(20)$ & $1(20)$ & \\
\hline \multicolumn{4}{|l|}{ Implant diameter } & \multirow{3}{*}{0.3} \\
\hline $3.7 \mathrm{~mm}$ & $5(100)$ & $3(60)$ & $4(80)$ & \\
\hline $3.2 \mathrm{~mm}$ & $0(0)$ & $2(40)$ & $1(20)$ & \\
\hline Ridge width (mm) & $5.9 \pm 0.5$ & $5.8 \pm 0.6$ & $5.7 \pm 0.6$ & 0.8 \\
\hline Ridge height (mm) & $18.2 \pm 1.1$ & $17.8 \pm 0.8$ & $17.7 \pm 1.5$ & 0.4 \\
\hline \multicolumn{4}{|c|}{ Preoperative bone density } & \multirow{3}{*}{0.8} \\
\hline D2 & $2(40)$ & $2(40)$ & $3(60)$ & \\
\hline D3 & $3(60)$ & $3(60)$ & $2(40)$ & \\
\hline
\end{tabular}

Data presented as mean $\pm S D$ or numbers, with percentages in parentheses.

No statistically significant difference was shown, $P$-value $\leq 0.05$
Table 2) $P D, S B I, P E S$, and VAS records

\begin{tabular}{|c|c|c|c|c|}
\hline & Group 1 & Group 2 & Group 3 & $P$ value \\
\hline \multicolumn{5}{|c|}{ PD } \\
\hline $\begin{array}{l}\text { Six months } \\
(\mathrm{mm})\end{array}$ & $2.6 \pm 0.2$ & $2.9 \pm 0.2$ & $3 \pm 0.6$ & 0.3 \\
\hline $\begin{array}{l}12 \text { months } \\
(\mathrm{mm})\end{array}$ & $3.2 \pm 0.4$ & $2.9 \pm 0.2$ & $3.3 \pm 0.4$ & 0.3 \\
\hline$P$ value & $0.03 *$ & 1 & 0.07 & \\
\hline \multicolumn{5}{|c|}{ SBI } \\
\hline Six months & $0.8 \pm 0.4$ & $0.6 \pm 0.6$ & $0.8 \pm 0.4$ & 0.7 \\
\hline 12 months & $0.6 \pm 0.5$ & $0.4 \pm 0.5$ & $0.4 \pm 0.5$ & 0.8 \\
\hline$P$ value & 0.4 & 0.4 & 0.2 & \\
\hline \multicolumn{5}{|c|}{ PES } \\
\hline 12 months & $10 \pm 0.7$ & $\begin{array}{c}11.2 \pm \\
0.8\end{array}$ & $10.8 \pm 0.09$ & 0.08 \\
\hline \multicolumn{5}{|c|}{ VAS } \\
\hline 12 months & $82 \pm 4.5$ & $85 \pm 5$ & $85 \pm 6.1$ & 0.9 \\
\hline
\end{tabular}

Data presented as mean $\pm S D$.

* Significant p-value $\leq 0.05$.

\section{Radiographic analysis}

\section{LBT evaluation}

The mean of LBT at the three points during the follow up period are presented in table (3) and figure (2). In all groups, LBT values decreased at the three time follow up periods. However, this decrease in the bone thickness has no significant difference between the three groups. Furthermore, LBT values showed non-significant difference within every group at the three measured points $(\mathrm{p}>0.05)$. 
Table (3): Comparison of LBT measurements among the study groups

\begin{tabular}{|c|c|c|c|c|c|c|c|c|c|c|c|c|}
\hline & \multicolumn{4}{|c|}{ At shoulder } & \multicolumn{4}{c|}{$3 \mathrm{~mm}$ apically } & \multicolumn{4}{c|}{5 mm apically } \\
\cline { 2 - 15 } & Immediate & $\begin{array}{c}\mathbf{6} \\
\text { months }\end{array}$ & $\begin{array}{c}\mathbf{1 2} \\
\text { months }\end{array}$ & $\begin{array}{c}\boldsymbol{P} \text { - } \\
\text { value }\end{array}$ & Immediate & $\mathbf{6}$ months & $\begin{array}{c}\mathbf{1 2} \\
\text { months }\end{array}$ & $\begin{array}{c}\boldsymbol{P} \text { - } \\
\text { value }\end{array}$ & Immediate & $\begin{array}{c}\mathbf{6} \\
\text { months }\end{array}$ & $\begin{array}{c}\mathbf{1 2} \\
\text { months }\end{array}$ & $\begin{array}{c}\boldsymbol{P} \text { - } \\
\text { value }\end{array}$ \\
\hline G 1 & $2.9 \pm 0.2$ & $2.5 \pm 0.1$ & $2.2 \pm 0.1$ & 0.3 & $3.3 \pm 0.2$ & $2.9 \pm 0.1$ & $2.6 \pm 0.1$ & 0.3 & $3.5 \pm 0.1$ & $3 \pm 0.1$ & $2.7 \pm 0.2$ & 0.2 \\
\hline G 2 & $2.8 \pm 0.1$ & $2.5 \pm 0.1$ & $2.2 \pm 0.2$ & 0.3 & $3.1 \pm 0.1$ & $2.8 \pm 0.2$ & $2.5 \pm 0.1$ & 0.6 & $3.5 \pm 0.1$ & $3.2 \pm 0.1$ & $2.7 \pm 0.4$ & 0.7 \\
\hline G 3 & $2.3 \pm 0.2$ & $2 \pm 0.2$ & $1.8 \pm 0.2$ & 0.6 & $2.5 \pm 0.1$ & $2.2 \pm 0.1$ & $1.9 \pm 0.1$ & 0.7 & $2.7 \pm 0.2$ & $2.4 \pm 0.1$ & $2.1 \pm 0.2$ & 0.8 \\
\hline$P$ value & 0.7 & 0.9 & 0.9 & & 0.5 & 0.3 & 0.7 & & 0.9 & 0.4 & 0.9 & \\
\hline
\end{tabular}

Data presented as mean $\pm S D$. Non-significant as all $P$-values $>0.05$

\section{Amount of bone resorption}

At the first and second time intervals, the amount of bone resorption was calculated and analyzed in Table 4. At the implant shoulder, the amount of bone resortpion was considered to be significant when compared between the three groups during the first interval period (immediate to six months), this representing more bone loss in the group 1 at this point $(P=0.003)$. At the second interval, the amount of bone loss was non-significant among the three groups. When comparing between the first and second intervals in every group, there was a significant bone loss at the implant shoulder site ( $P=0.02)$ only in group 1, while the difference between the two intervals was non-significant in groups 2 and 3. The amount of bone loss at $3 \mathrm{~mm}$ and $5 \mathrm{~mm}$ apical to the shoulder were considered to be non-significant among the three groups. In addition, the difference between the two intervals was also non-significant in every group.

Table 4. Amount of bone resorption in the three groups during the first and second intervals

\begin{tabular}{|c|c|c|c|c|c|c|c|c|c|}
\hline & \multicolumn{4}{|c|}{ At shoulder } & \multicolumn{3}{c|}{$3 \mathrm{~mm}$ apically } & \multicolumn{3}{c|}{5 mm apically } \\
\hline & $\mathbf{1}^{\text {st }}$ interval & $\mathbf{2}^{\text {nd }}$ interval & $\boldsymbol{P}$ value & $\mathbf{1}^{\text {st }}$ interval & $\mathbf{2}^{\text {nd }}$ interval & P value & $\mathbf{1}^{\text {st }}$ interval & $\mathbf{2}^{\text {nd }}$ interval & P value \\
\hline G1 & $-0.4 \pm 0.07$ & $-0.3 \pm 0.06$ & $0.02 *$ & $-0.3 \pm 0.1$ & $-0.3 \pm 0.07$ & 0.8 & $-0.4 \pm 0.1$ & $-0.3 \pm 0.09$ & 0.09 \\
\hline G2 & $-0.3 \pm 0.1$ & $-0.3 \pm 0.04$ & 0.5 & $-0.3 \pm 0.04$ & $-0.2 \pm 0.04$ & 0.054 & $-0.3 \pm 0.05$ & $-0.3 \pm 0.08$ & 0.3 \\
\hline G3 & $-0.2 \pm 0.03$ & $-0.3 \pm 0.05$ & 0.3 & $-0.3 \pm 0.03$ & $-0.3 \pm 0.07$ & 0.8 & $-0.3 \pm 0.06$ & $-0.3 \pm 0.08$ & 0.9 \\
\hline P value & $0.003^{*}$ & 0.5 & & 0.3 & 0.3 & & 0.07 & 0.9 & \\
\hline
\end{tabular}

Data expressed as mean $\pm S D . \quad *$ Significant $p$-value $\leq 0.05$ 


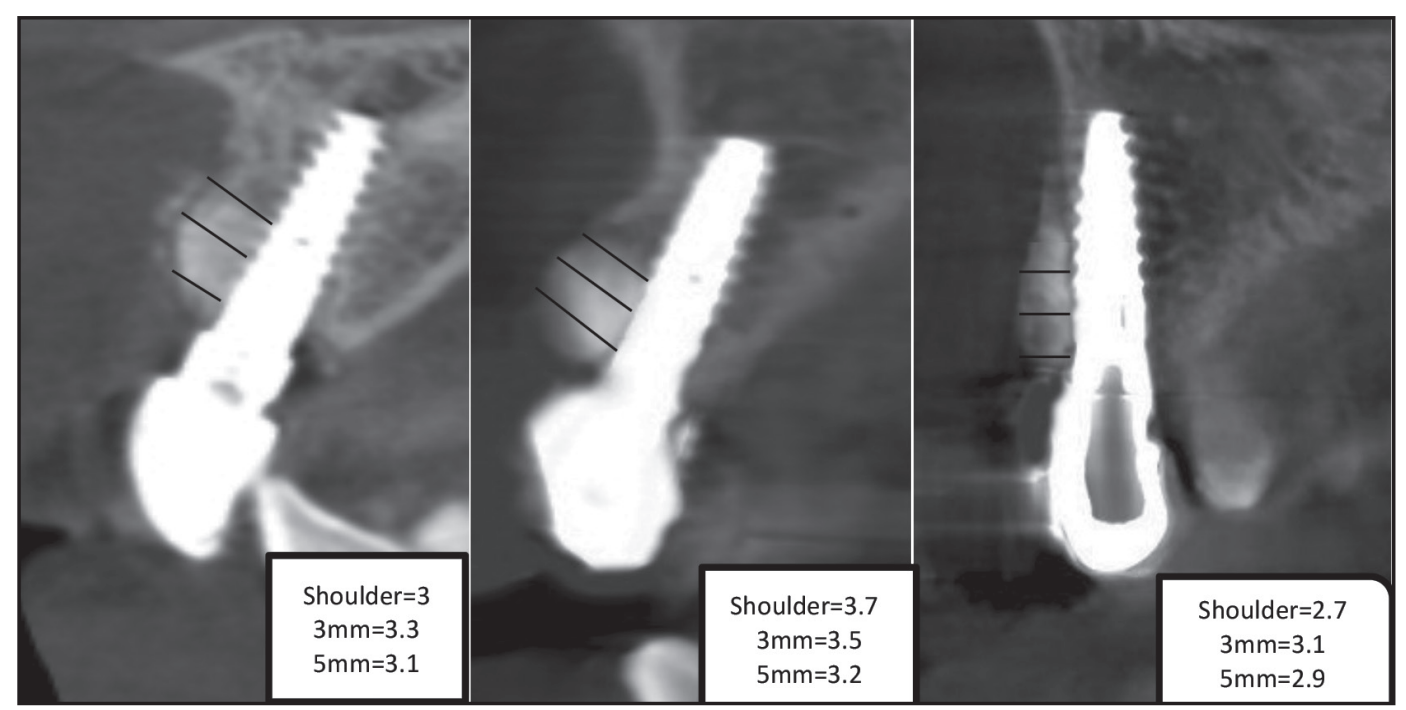

Figure (2) CBCTs showing the LBT in G1, G2, and G3 respectively at 12 months follow up.

\section{DISCUSSION}

Esthetic restoration of a single anterior tooth with implant is considered a challenging procedure in dental practice. Alveolar bone resorption following anterior teeth loss usually endangers gingival tissue levels, thus compromising the esthetic outcomes of the implant restoration. In the last decade, creation of an implant borne restoration to be indistinguishable from the surrounding natural teeth in the esthetic zone is as important as the implant survival rates. For successful implant therapy in the anterior esthetic zone of the maxilla, the implant should be placed in a proper 3 dimensional position within the available alveolar bone. In cases of insufficient bone, simultaneous or delayed bone augmentation are usually considered mandatory to allow implant insertion in a proper position; however, hard tissue may undergo resorption and in turn causes soft tissue changes which affect esthetic outcomes ${ }^{(20)}$.

Creation and preservation of adequate labial bone ${ }^{(21)}$ in the esthetic zone is of great importance, because it has a significant role in supporting the peri-implant gingival tissue which in turn should be continuous with the adjacent soft tissues to achieve excellent esthetics ${ }^{(22)}$. Many authors reported that insertion of dental implants in the esthetic zone of the maxilla usually requires GBR to avoid gingival recession which caused by alveolar bone resorption following tooth extraction ${ }^{(23)}$, this soft tissue recession can be decreased if the LBT is more than $2 \mathrm{~mm}$. (24) Autogenous bone grafts have been reported to be the most successful material in bone regeneration procedures in dental implantology ${ }^{(25)}$. However, several limitations have been encountered including restricted donor sites, unpredictable available bone volume especially from intraoral bone grafts, and possible donor site morbidity such as infection, prolonged wound drainage, and large hematomas (26). Therefore, in the present study BBGS was used as an adjunct to autogenous bone in all patients. Many authors ${ }^{(27)}$ reported that the effect of both autograft and xenograft appears to be comparable in bone augmentation. Bovine bone graft has a chemical components and architectural skeleton similar to that of the bone of the human being. In addition, bovine bone stimulates new bone formation to be continuous with the graft ${ }^{(28)}$.

It has been reported that, BBGS is usually associated with very slow degradation rate, up to 3 to 4 years, so the healing in the grafted defects is usually characterized the presence of the graft remnants 
which invaded the newly formed bone, instead of being completely replaced with the regenerated bone. In this study, the BBGS was formed from bovine cancellous bone which is more porous than the granules of the bovine cortical bone. According to Venkataraman et al., ${ }^{(29)}$, the higher the porosity, the great will be the osteoconductivity of the bone graft, becuase it stimulates faster bone formation around the implants. Miron et $\mathbf{a l}^{(30)}$ reported that PRF membrane is considered as a valuable alternative to non-resorbable and resorbable membranes. In this study, it was observed that PRF membrane in combination with BBGS is an adequate method for labial bone augmentation and gingival tissue preservation that achieved good functional and esthetic outcomes. Similar observations were also reported by another study ${ }^{(31)}$. Furthermore, the results of the current study revealed that simultaneous placement of BBGS and PRF with dental implants resulted in lower rate of bone resorption which has a great role in the successful clinical stability and osseointegration that were achieved in all cases, proving that the survival rate of dental implant is not affected by the time of implant placement after tooth extraction. Similar findings are also reported by many authors $(32,33)$.

In this study, it was noted that the value of LBT was comparable in the three groups during the follow up period, meaning that it was possible to preserve the labial bone over the implant defects with the use of BBGS and PRF membrane, even if the original labial bone had been resorbed and this augmented bone functioned as a stable new labial bone for 12 months. These results are in line with the findings of many authors ${ }^{(34)}$. Furthermore, the mean value of the LBT in the three groups was comparable with that observed by other studies ${ }^{(35,36)}$ who reported that the mean value of LBT was $3 \mathrm{~mm}$ and $2.12 \mathrm{~mm}$, respectively. On contrary, Meijer et al., (37) observed in their study much less LBT, which is around $1 \mathrm{~mm}$. All these studies were conducted on immediate dental implants. In another study (38) the LBT of the natural incisors was $0.6-0.8 \mathrm{~mm}$ in the cervical, $4 \mathrm{~mm}$ in apical direction. The LBT in the current study was observed to be thicker than that at natural teeth. This may be due to the palatal insertion of the implants, the application of BBGS with PRF membrane on the labial bone surface, and filling the buccal space that was present between the immediate implant and the labial wall of the extracted socket. Those procedures resulted in an adequate formation and preservation of labial bone for 12 months. This explanation was also stated by Slagter et al. ${ }^{(34)}$

Despite the LBT had insignificant difference among the three groups at the three different points; in group 1, the amount of bone resorption at the implant shoulder showed significant difference when compared to the other two groups ( $P$ value $=0.003$ ), only during the first interval (immediate to six months), and without any significant changes in the second interval (six to 12 months), denoting that immediate implant placement cannot prevent the normal bone resorption that usually occurs immediately after tooth extraction, even with the use of PRF and BBGS as approved by Degidi et al ${ }^{(36)}$. The same results were also recorded by many investigators ${ }^{(39,40)}$ who observed that immediate implant placement was accompanied by labial bone loss in both height and width within the first millimeters along the implant axis within six months. Furthermore, many other studies on immediate implant insertion in the esthetic zone of the maxilla, with long term follow-up, observed extreme difference in LBT, as well as complete resorption of the labial bone ${ }^{(23,41,42)}$.

Clinical soft tissue outcomes revealed comparable PD and SBI values in all groups. In addition, esthetic appearance which is evaluated with PES, showed high scores without a significant difference between the three groups, which means that timing of implant placement, did not affect the esthetic outcomes as also concluded by many authors (22,43) who observed that comparable esthetic results of the surrounding soft tissue can be achieved with all treatment timing protocols of implant placement 
in the anterior maxilla. These adequate clinical features were achieved because of the preservation of labial bone layer over the implant in all groups for 12 months, as it provides support to the gingival tissues. On contrary, in another study ${ }^{(44)}$ it was observed that irrespective of the timing of dental implant placement in the anterior esthetic zone of maxilla, esthetic failures were more common and only a few cases showed perfect results.

\section{CONCLUSION}

Preservation of LBT at dental implants in the esthetic zone of the maxilla appears to be independent on the time of implant insertion after tooth extraction. It was possible to develop and maintain a stable labial bone layer over the implant surface, for 12 months, with the use of BBGS and PRF membrane.

\section{REFERENCES}

1. Januário A L, Duarte W R, Barriviera M, Mesti J C, Araújo M G, Lindhe J. Dimension of the facial bone wall in the anterior maxilla: a cone-beam computed tomography study. Clin Oral Implants Res 2011; 22: 1168-71.

2. Fuentes R, Flores T, Navarro P, Salamanca C, Beltrán V, Borie E. Assessment of buccal bone thickness of aesthetic maxillary region: a cone-beam computed tomography study. J Periodontal Impl Sci 2015; 45:162-8.

3. Misawa M, Lindhe J, Araújo M G. The alveolar process following single-tooth extraction: a study of maxillary incisor and premolar sites in man. Clin Oral Impl Res 2016; 27: 884-9.

4. Callan DP, Rohrer MD. Use of bovine-derived hydroxyapatite in the treatment of edentulous ridge defects: a human clinical and histologic case report. J Periodontol 1993; 64: 575-82.

5. Misch CE, Dietsh F. Bone-grafting materials in implant dentistry. Implant Dent 1993; 2: 158-67.

6. Buser D, Ingimarsson S, Dula K , Lussi A, Hirt H P, Belser U. Long-term stability of osseointegrated implants in augmented bone: a 5-year prospective study in partially edentulous patients. Int J Periodontics Rest Dent.2002; 22.

7. Gassling V, Douglas T, Warnke H, Açil Y, Wiltfang J, Becker T. Platelet-rich fibrin membranes as scaffolds for periosteal tissue engineering. Clin Oral Impl Res.2010; 21: 543-9.
8. Gupta V, Bains K, Singh P, Mathur A, Bains R. Regenerative potential of platelet rich fibrin in dentistry: Literature review. Asian J Oral Heal Allied Sci. 2011; 1: 23-8.

9. Dohan D, Choukroun J, Diss A, et al. Platelet-rich fibrin (PRF): A second-generation platelet concentrate. Part II: Platelet-related biologic features. Oral Surg Oral Med Oral Pathol Oral Radiol Endod 2006; 101: 45-50.

10. Valente F, Schiroli G, Sbrenna A. Accuracy of computeraided oral implant surgery: a clinical and radiographic study. Int J Oral Maxillofac Surg 2009; 1: 24.

11. Hof M, Pommer B, Strbac GD, Sütö D, Watzek G, Zechner W. Esthetic evaluation of single-tooth implants in the anterior maxilla following autologous bone augmentation. Clin Oral Implants Res 2013; 24: 88-93.

12. Cosyn J, Hooghe N, De Bruyn H. A systematic review on the frequency of advanced recession following single immediate implant treatment. J Clin Periodontol. 2012; 39:582-9.

13. Levine R, William M. Esthetic risk assessment in implant dentistry. Inside Dent.2012; 8: 66-71.

14. 14-Lobbezoo F, Brouwers JE, Cune MS, Naejie M. Dental implants in patients with bruxing habits. J Oral Rehabil. 2006; 33:152-9.

15. Dohan Ehrenfest DM, Del Corso M, Diss A, Mouhyi J, Charrier J-B. Three-Dimensional Architecture and Cell Composition of a Choukroun's Platelet-Rich Fibrin Clot and Membrane. J Periodontol. 2010;81:546-55.

16. Andrew W, Michael, Geoffrey H, Warrick B, Hilary B. The evaluation of processed cancellous bovine bone as a bone graft substitute. Clin. Oral Impl. Res. 2005;16:379-86.

17. Barone A, Ricci M, Romanos GE, Tonelli P, Alfonsi F, Covani U. Buccal bone deficiency in fresh extraction sockets: A prospective single cohort study. Clin Oral Implants Res. 2015;26:823-30.

18. Belser UC, Grütter L, Vailati F, Bornstein MM, Weber H-P, Buser D. Outcome Evaluation of Early Placed Maxillary Anterior Single-Tooth Implants Using Objective Esthetic Criteria: A Cross-Sectional, Retrospective Study in 45 Patients With a 2- to 4-Year Follow-Up Using Pink and White Esthetic Scores. J Periodontol. 2009;80:140-51.

19. Al-Dosari A, Al-Rowis R, Moslem F, Alshehri F, Ballo AM. Esthetic outcome for maxillary anterior single implants assessed by different dental specialists. J Adv Prosthodont. 2016;8:345-53.

20. Grunder U, Researcher I, Capelli M. Influence of 3-D Boneto-Implant Relationship on Esthetics. Int J Periodontics Restorative Dent.2005;25:113-9. 
21. Buser D, Martin W, Belser UC. Optimizing esthetics for implant restorations in the anterior maxilla: anatomic and surgical considerations. Int $\mathrm{J}$ Oral Maxillofac Implant 2004; 19: 43-61.

22. Den Hartog L, Huddleston Slater JJR, Vissink A, Meijer HJA, Raghoebar GM. Treatment outcome of immediate, early and conventional single-tooth implants in the aesthetic zone: A systematic review to survival, bone level, soft-tissue, aesthetics and patient satisfaction. J Clin Periodontol 2008; 35: 1073-86.

23. Raes S, Eghbali A, Chappuis V, Raes F, De Bruyn H, Cosyn J. A long- term prospective cohort study on immediately restored single tooth implants inserted in extraction sockets and healed ridges: $\mathrm{CBCT}$ analyses, soft tissue alterations, aesthetic ratings, and patient-reported outcomes. Clin Implant Dent Relat Res. 2018;20:522-30.

24. Yasukazu M, Tadakazu O. Dental Cone Beam Computed Tomography Analyses of Postoperative Labial Bone Thickness in Maxillary Anterior Implants: Comparing Immediate and Delayed Implant Placement. Int J Periodontics Restorative Dent 2011; 31: 215-25.

25. Sakkas A, Wilde F, Heufelder M, Winter K, Schramm A. Autogenous bone grafts in oral implantology-is it still a "gold standard"? A consecutive review of 279 patients with 456 clinical procedures. Int J Implant Dent 2017; 3: 1-17.

26. Nkenke E, Schultze-Mosgau S, Radespiel-Tiöger M, Kloss F, Neukam FW. Morbidity of harvesting of chin grafts: A prospective study. Clin Oral Implants Res. 2001; 12: 495-02

27. Lutz R, Berger-Fink S, Stockmann P, Neukam FW, Schlegel KA. Sinus floor augmentation with autogenous bone vs. a bovine-derived xenograft - a 5-year retrospective study. Clin Oral Implants Res 2015; 26: 644-8.

28. Haugen HJ, Lyngstadaas SP, Rossi F, Perale G. Bone grafts: which is the ideal biomaterial?. J Clin Periodontol. 2019;46:92-02.

29. Venkataraman N, Bansal S, Bansal P, Narayan S. dynamics of bone graft healing around implants. J Int Clin Dent Res Org 2015;7: 40-7.

30. Miron RJ, Pikos MA. PRF as a barrier membrane in guided bone regeneration. Dent Today. 2017;36:216-25.

31. Groot PPG De, Remijn JA. Successful soft and hard tissue augmentation with platelet - rich fibrin in combination with bovine bone space maintainer in a delayed implant placement protocol in the esthetic zone: A case report. 2019; 4: 1185-90.

32. Palattella P, Torsello F, Cordaro L. Two- year prospective clinical comparison of immediate replacement vs. immediate restoration of single tooth in the esthetic zone. Clin Oral Implants Res.2008;19: 1148-53.
33. Block M, Mercante D, Lirette D, Mohamed W, Ryser M, Castellon P. Prospective Evaluation of Immediate and Delayed Provisional Single Tooth Restorations. J Oral Maxillofac Surg 2009; 67: 89-07.

34. Slagter KW, Raghoebar GM, Bakker NA, Vissink A, Meijer HJA. Buccal bone thickness at dental implants in the aesthetic zone: A 1-year follow-up cone beam computed tomography study. J Cranio-Maxillofacial Surg. 2017;45:13-9.

35. Sarnachiaro GO, Chu SJ, Sarnachiaro E, Gotta SL, Tarnow DP. Immediate implant placement into extraction sockets with labial plate dehiscence defects: a clinical case series. Clin Implant Dent Relat Res. 2016; 18: 821-9.

36. Degidi M, Daprile G, Nardi D, Piattelli A. Buccal bone plate in immediately placed and restored implant with BioOss ${ }^{\circledR}$ collagen graft: A 1-year follow-up study. Clin Oral Implants Res 2013; 24: 1201-5.

37. Meijer HJA, Slagter KW, Vissink A Raghoebar GM. Buccal bone thickness at dental implants in the maxillary anterior region with large bony defects at time of immediate implant placement: A 1-year cohort study. Clin Implant Dent Relat Res 2018; 1-7.

38. El Nahass H., Naiem S. Analysis of the dimensions of the labial bone wall in the anterior maxilla: a cone-beam computed tomography study. Clin oral implants res 2015; 26: 57-61.

39. Mazzocco F, Jimenez D, Barallat L, Paniz G, Fabbro MD, Nart J. Bone volume changes after immediate implant placement with or without flap elevation. Clin Oral Implants Res. 2017; 28: 495-01.

40. Covani U, Cornelini R, Barone A. Bucco-Lingual Bone Remodeling Around Implants Placed into Immediate Extraction Sockets: A Case Series. J Periodontol 2003; 74: 268-73.

41. Benic GI, Mokti M, Chen CJ, Weber HP, Hämmerle CH, Gallucci GO. Dimensions of buccal bone and mucosa at immediately placed implants after 7 years: a clinical and cone beam computed tomography study. Clin Oral Implants Res 2012; 23: 560-6.

42. Groenendijk E, Staas TA, Graauwmans FEJ, et al. Immediate implant placement: the fate of the buccal crest. A retrospective cone beam computed tomography study. Int J Oral Maxillofac Surg 2017; 46: 1600-6.

43. Boardman N, Darby I, Chen S. A retrospective evaluation of aesthetic outcomes for single-tooth implants in the anterior maxilla. Clin Oral Implants Res 2016; 27: 443-51.

44. -Raes F, Cosyn J, Crommelinck E, Coessens P, De Bruyn $\mathrm{H}$. Immediate and conventional single implant treatment in the anterior maxilla: 1-Year results of a case series on hard and soft tissue response and aesthetics. J Clin Periodontol 2011; 38: 385-94. 